\title{
DESKRIPSI TATA LETAK PROYEKTOR DAN PENCAHAYAAN DI RUANG KELAS SERTA KELUHAN KELELAHAN MATA MAHASISWA/I
}

\author{
Anggit Nugroho' ${ }^{1}$, Faisal Syahrian ${ }^{2}$ \\ ${ }^{1,2}$ Program Studi Diploma Tiga Refrasi Optisi STIKes Dharma Husada Bandung \\ ${ }^{1}$ raffa.refraksionis@gmail.com
}

\begin{abstract}
Eye fatigue (asthenopia) is a disorder of vision function. the causes and symptoms are very diverse which involve physical, physiological, psychological, social factors. Ergonomic classrooms are important in creating a teaching and learning process. Factors that affect the ergonomic aspects of the projector screen, including the viewing angle (visual angle) and brightness. The purpose of this study is to Describe the Complaints of Eye Fatigue of Students Against the Layout of Projectors, Enthusiasts in Classrooms STIKes Dharma Husada Bandung in 2019. This research method is descriptive, using primary data, through questionnaire instruments, total sample 100. Collected data are analyzed univariately. The results of the study in 7 STIKes Dharma Husada Bandung classrooms, the lighting did not meet the standard (144lux). The measurement of the projector's horizontal and vertical angles is still below the standard. Complaints of eye fatigue that occurred in STIKes Dharma Husada Bandung highest among them were shoulder pain as many as 84 respondents (84\%) and at least complaints of dizziness accompanied by nausea of 28 respondents (28\%). Classroom lighting is in accordance with the standards and layout of the projector in accordance with vertical and horizontal angles so as to reduce complaints of eye fatigue for students of STIKes Dharma Husada Bandung.
\end{abstract}

Keywords: Eye fatigue, ergonomic projector screen

\begin{abstract}
ABSTRAK
Kelelahan mata ( asthenopia) merupakan gangguan fungsi penglihatan. penyebab dan gejalanya sangat majemuk yang melibatkan faktor fisik, fisiologis, psikologis, faktor sosial. Ruang kelas yang ergonomis merupakan hal penting dalam menciptakan proses belajar mengajar. Faktor yang mempengaruhi aspek ergonomis dari layar proyektor, meliputi sudut pandang (visual angle) dan kecerahan. Tujuan penelitian ini untuk Deskripsi Keluhan Kelelahan Mata Mahasiswa/i Terhadap Tata Letak Proyektor, Pencaayaan di Ruang Kelas STIKes Dharma Husada Bandung Tahun 2019. Metode Penelitian ini bersifat deskriptif, menggunakan data primer, melalui instrumen kuesioner, Jumlah sample 100. Data terkumpul dianalisis secara univariat. Hasil penelitian di 7 ruang kelas STIKes Dharma Husada Bandung, pencahayaannya belum memenuhi standar(144 lux). Pengukuran letak proyektor sudut horizontal dan vertikal masih di bawah standar. Keluhan Kelelahan mata yang terjadi di STIKes Dharma Husada Bandung tertinggi diantaranya bahu terasa nyeri sebanyak 84 responden (84\%) dan paling sedikit keluhan pusing disertai mual sebanyak 28 responden (28\%). Pencahayaan ruang kelas sesuai standar serta tata letak proyektor sesuai dengan sudut vertikal dan horiontal sehingga dapat mengurangi keluhan kelelahan mata mashasiswa/i STIKes Dharma Husada Bandung.
\end{abstract}

Kata Kunci : Kelelahan mata, ergonomis layar proyektor

\section{PENDAHULUAN}

Gangguan terhadap penglihatan 
banyak terjadi, mulai dari gangguan ringan hingga gangguan berat yang dapat mengakibatkan kebutaan. Kelelahan mata (asthenopia) merupakan gangguan fungsi penglihatan dengan penyebab dan gejala yang sangat majemuk yang melibatkan faktor fisik, fisiologis, psikologis, bahkan faktor sosial. Kelelahan mata adalah gejala - gejala yang dilibatkan oleh upaya-upaya berlebihan untuk memperoleh ketajaman binokuler yang sebaik-baiknya dari sistem penglihatan yang berada dalam keadaan kurang sempurna.

Ruang kelas yang ergonomis merupakan faktor penting dalam menciptakan proses belajar mengajar agar sesuai dengan tujuan yang diharapkan. Suatu ruang kelas biasanya terdiri dari sarana fisik dan nonfisik. sarana nonfisik seperti suasana perkuliahan, pencahayaaan, kebisingan, kegaduhan, temperatur dan lain juga mempengaruhi nuansa proses belajar yang efektif.

Media pembelajaran di ruang kelas pada kampus-kampus perguruan tinggi pada umumnya berkembang seiring dengan perkembangan teknologi. Keberadaan proyektor (OHP) over head projector yang populer di tahun 1990-an telah gantikan oleh proyektor LCD sejak era tahun 2000an. Perangkat proyektor (LCD) liquid crystal display merupakan media pembelajaran yang populer digunakan di kampus Perguruan Tinggi. Display LCD memiliki banyak keunggulan dan penggunaannya diyakini dapat meningkatkan pemahaman mahasiswa dalam belajar di ruang kelas. Posisi letak perangkat proyektor perlu diperhatikan karena akan mempengaruhi efektifitas penggunaannya. Tujuan penelitian ini adalah mengevaluasi pencahayaan dan memberikan usulan ergonomis tata letak perangkat proyektor LCD di ruang kelas. Objek studi kasus adalah ruang kelas. Ada dua pendekatan yang digunakan dalam analisis. Pendekatan subjektif untuk mengevaluasi efektifitas posisi layar proyektor sekarang berdasarkan persepsi mahasiswa. Pendekatan objektif untuk menganalisis kesesuaian antropometri pengguna, sudut pandang dan paparan pencahayaan. Analisis menunjukkan posisi perangkat proyektor LCD di ruang kelas dan laboratorium komputer secara umum belum memenuhi kaidah-kaidah ergonomi. (syamsul \& ira, 2015).

Kebanyakan dari para mahasiswa/i mengeluh tentang tata letak proyektor dan pencahayaan serta ketajaman, yang menyebabkan mata harus berkonsentrasi penuh untuk memfokuskan objek yang tampil diproyektor. Bila hal ini terus menerus terjadi dapat mengakibatkan kelelahan mata dan dalam jangka panjang menyebabkan kelainan refraksi (B. Ralph , 2012).

Berdasarkan penelitian Agus dan kawan - kawan menyatakan sebagian besar mahasiswa program studi pendidikan dokter fakultas kedokteran Universitas Udayana tahun 2014, (63,9\%) menyatakan bahwa kondisi layar proyektor kurang sesuai untuk proses perkuliahan. 
Kecerahan layar merupakan faktor utama ketidaksesuaian layar proyektor, sebagaimana dinyatakan $63,4 \%$ mahasiswa.

Penelitian Wu (2011) menunjukkan bahwa terdapat beberapa faktor yang mempengaruhi aspek ergonomis dari layar proyektor, meliputi sudut pandang (visual angle) dan kecerahan. Penelitian tersebut juga menunjukkan bahwa perbedaan yang terlalu besar antara pencahayaan ruangan dan kecerahan layar dapat menimbulkan kelelahan pada mata. Oleh karena itu, diperlukan kombinasi pencahayaan ruangan dan kecerahan layar yang optimal untuk mencegah terjadinya hal tersebut (Agus \& I made, 2017).

Survey awal terhadap perangkat proyektor LCD di kampus STIKes DHB ditemukan beberapa permasalahan, posisi letak peralatan LCD yang terlalu tinggi dan terlalu menjorok ke samping serta pencahayaan ruang kelas yang kurang terang. Dosen ataupun mahasiswa mengalami kelelahan penglihatan serta memaksa penglihatan secara terus menerus ke samping, posisi layar proyektor pada beberapa ruang kelas dan berada di dekat jendela sehingga berpotensi terhadap kondisi silau yang dapat mengurangi efektifitas penglihatan. Jarak kursi kuliah yang terlalu dekat ke layar proyektor dapat mengakibatkan ketidaknyamanan postur (postural discomfort) terutama pada bagian leher bagi mahasiswa yang duduk di baris terdepan. Permasalahan ini akan dapat menjadikan penggunaan teknologi tersebut menjadi kurang efektif. Untuk itu perlu dilakukan evaluasi atau penilaian ergonomi terhadap posisi perangkat proyektor dalam bentuk studi kasus.

Dari hasil studi pendahuluan pada bulan Maret 2019, pada mahasiswa STIKes Dharma Husada Bandung tahun 2019, 8 dari 10 mahasiswa STIKes Dharma Husada Bandung mengalami gejala - gejala kelelahan mata. Diantaranya 3 responden mengalami bahu terasa nyeri, 2 responden mengalami pandangan berbayang, 2 responden mengalami mata sulit dalam memfokuskan, dan 1 responden mengalami mata terasa perih.

Penelitian ini bertiujuan memperoleh informasi tentang deskripsi tata letak proyektor dan pencahayaan di ruang kelas serta keluhan kelelahan mata mahasis/i STIKes Dharma Husada

\section{METODE PENELITIAN}

Kerangka konsep pada penelitian ini dibatasi intensitas pencahayaan dan keluhan kelelahan mata. Penelitian bersifat deskriptif kuantitatif untuk mendapatkan gambaran dan keterangan-keterangan mengenai tata letak proyektor dan kelelahan mata pada mahasiswa /i STIKes Dharma Husada.

Pendekatan waktu pengumpulan data secara Cross sectional, dimana observasi atau pengumpulan data sekaligus pada suatu saat. Pupulasi penelitian yaitu mahasiswa STIKes DHB progam studi Diploma Tiga Refraksi Optisi, Diploma Tiga kebidanan , Diploma Tiga Keperawatan, S1 Kesehatan 
Masyrakat, dan S1 Keperawatan. Yang semuanya Berjumalah 1500 mahasiswa dan yang di teliti 100 orang dari masing masing program studi sebanyak 20 orang tingkat 2-3. Sampel diambil secara total sampling yaitu, menjadikan seluruh populasi yang ada untuk menjadi sampel dalam penelitian ini. Variabel yang dideskripsikan adalah tata letak proyektor terhadap kelelahan mata dengan tata letak proyektor sebelum dan sesudah dilakukan pengukuran.

\section{HASIL DAN PEMBAHASAN}

Tabel 1 Pengukuran Pencahayaan Ruang Kelas di STIKes Dharma Husada Bandung Tahun 2019.

\begin{tabular}{|c|c|c|c|}
\hline \multirow[t]{2}{*}{$\begin{array}{c}\text { Kondisi } \\
\text { Pengukuran }\end{array}$} & \multicolumn{2}{|c|}{$\begin{array}{c}\text { Rata-rata } \\
\text { Tingkat Pencahayaan }\end{array}$} & \multirow[t]{2}{*}{$\begin{array}{c}\text { Total } \\
\text { Rata-rata }\end{array}$} \\
\hline & Lantai & Dinding & \\
\hline \multicolumn{4}{|l|}{ Kelas B103 } \\
\hline Tanpa Penerangan & $8.5 \operatorname{lux}$ & 10.78 lux & 9.64 lux \\
\hline Dengan Penerangan & 70.75 lux & 89.28 lux & 80.015 lux \\
\hline \multicolumn{4}{|l|}{ Kelas B201 } \\
\hline Tanpa Penerangan & $19.8 \operatorname{lux}$ & $42.13 \operatorname{lux}$ & 30.965 lux \\
\hline Dengan Penerangan & $66.5 \operatorname{lux}$ & 386.995 lux & $226.7475 \operatorname{lux}$ \\
\hline \multicolumn{4}{|l|}{ Kelas D204 } \\
\hline Tanpa Penerangan & $76.5 \operatorname{lux}$ & $61.08 \operatorname{lux}$ & $68.79 \operatorname{lux}$ \\
\hline Dengan Penerangan & $158.5 \operatorname{lux}$ & $152.55 \operatorname{lux}$ & $155.525 \operatorname{lux}$ \\
\hline \multicolumn{4}{|l|}{ Kelas D302 } \\
\hline Tanpa Penerangan & $77 \operatorname{lux}$ & 88.41 lux & $82.705 \operatorname{lux}$ \\
\hline Dengan Penerangan & 133.25 lux & $204.08 \operatorname{lux}$ & $168.665 \operatorname{lux}$ \\
\hline \multicolumn{4}{|l|}{ Kelas C302 } \\
\hline Tanpa Penerangan & $13 \operatorname{lux}$ & $31.83 \operatorname{lux}$ & $22.415 \operatorname{lux}$ \\
\hline Dengan Penerangan & $54.75 \operatorname{lux}$ & $50.66 \operatorname{lux}$ & $52.705 \operatorname{lux}$ \\
\hline \multicolumn{4}{|l|}{ Kelas C202 } \\
\hline Tanpa Penerangan & $23.4 \operatorname{lux}$ & $38.245 \operatorname{lux}$ & $30.82 \operatorname{lux}$ \\
\hline Dengan Penerangan & $79.5 \operatorname{lux}$ & 135.499 lux & 107.499 lux \\
\hline \multicolumn{4}{|l|}{ Kelas A101 } \\
\hline Tanpa Penerangan & - & - & - \\
\hline Dengan Penerangan & $44 \operatorname{lux}$ & 223.705 & 133.852 lux \\
\hline
\end{tabular}

Berdasarkan tabel 1, nilai rata - rata intensitas pencahayaan ruang kelas baik tanpa penerangan buatan (lampu) maupun dengan menggunakan penerangan buatan (lampu), tidak memenuhi standar, karena menurut SNI 03-6197-2000 tahun 2011 seharusnya untuk standar pencahayaan ruang kelas memiliki pencahyaan sebesar 300 lux.

Adapun penerangan di ruang kelas B201 dengan penerangan dari lampu, tingkat penerangan pada dinding dikategorikan memenuhi syarat yaitu 386.995 lux. Namun apabila dihitung rata-ratanya tetap tidak 
memenuhi syarat yaitu 226.7475 lux.

Tabel 2 Ditribusi Frekuensi Keluhan yang dirasakan Mahasiswa /i akibat Tata letak Proyektor dan Pencahayaan STIKes Dharma Husada Bandung Tahun 2019.

\begin{tabular}{lcccc}
\hline \multicolumn{1}{c}{ Jenis Keluhan } & \multicolumn{2}{c}{ Mengalami } & \multicolumn{2}{c}{ Tidak Mengalami } \\
\cline { 2 - 4 } & Jumlah & Persen (\%) & Jumlah & Persen (\%) \\
\hline Nyeri, terasa berdenyut di sekitar mata & $\mathbf{3 0}$ & $\mathbf{3 0 \%}$ & $\mathbf{7 0}$ & $\mathbf{7 0 \%}$ \\
\hline $\begin{array}{l}\text { Pandanga menjadi kabur memeperhatikan } \\
\text { slide proyektor dari arah samping }\end{array}$ & $\mathbf{7 6}$ & $\mathbf{7 6 \%}$ & $\mathbf{2 4}$ & $\mathbf{2 4 \%}$ \\
\hline $\begin{array}{l}\text { Pandangan berbayang memperhatikan Slide } \\
\text { proyektor dari arah samping }\end{array}$ & $\mathbf{7 0}$ & $\mathbf{7 0 \%}$ & $\mathbf{3 0}$ & $\mathbf{3 0 \%}$ \\
\hline $\begin{array}{l}\text { Sulit memfokuskan penglihatan Setelah } \\
\text { memperhatikan slide proyektor dari arah } \\
\text { samping }\end{array}$ & $\mathbf{7 9}$ & $\mathbf{7 9 \%}$ & $\mathbf{2 1}$ & $\mathbf{2 1 \%}$ \\
\hline $\begin{array}{l}\text { Mata teraasa perih Memperhatikan slide } \\
\text { proyektor Dari arah samping }\end{array}$ & $\mathbf{7 9}$ & $\mathbf{7 9 \%}$ & $\mathbf{2 1}$ & $\mathbf{2 1 \%}$ \\
\hline $\begin{array}{l}\text { Mata terlihata menjadi merah Memperhatikan } \\
\text { slide proyektor dari arah samping }\end{array}$ & $\mathbf{2 5}$ & $\mathbf{2 5 \%}$ & $\mathbf{7 5}$ & $\mathbf{7 5 \%}$ \\
\hline $\begin{array}{l}\text { Bahu terasa nyeri setelah meperhatikan slide } \\
\text { proyektor Dari arah samping }\end{array}$ & $\mathbf{8 4}$ & $\mathbf{8 4 \%}$ & $\mathbf{1 6}$ & $\mathbf{1 6 \%}$ \\
\hline $\begin{array}{l}\text { Sakit kepala setelah Memperhatikan slide } \\
\text { Proyektor dari arah samping }\end{array}$ & $\mathbf{7 4}$ & $\mathbf{7 4 \%}$ & $\mathbf{2 6}$ & $\mathbf{2 6 \%}$ \\
\hline $\begin{array}{l}\text { Pusing disertai mual memperhatikan slide } \\
\text { Proyektor dari arah samping }\end{array}$ & $\mathbf{2 8}$ & $\mathbf{2 8 \%}$ & $\mathbf{7 2}$ & $\mathbf{7 2 \%}$ \\
\hline
\end{tabular}

Keluhan yang paling banyak dirasakan mahasiswa/i akibar tata letak proyektor adalah Bahu terasa nyeri setelah memperhatikan slide proyektor dari arah samping (84\%). Sedangkan keluhan yang paling banyak dirasakan akibat pencahayaan adalah mata Sulit memfokuskan penglihatan Setelah memperhatikan slide proyektor dari arah samping (79\%) dan Mata teraasa perih Memperhatikan slide proyektor dari arah samping $(79 \%)$

\section{Tabel 3 Pengukuruan Letak Sudut Horizontal dan Vertikal Proyektor di} Ruang Kelas STIKes Dharma Husada Bandung Tahun 2019.

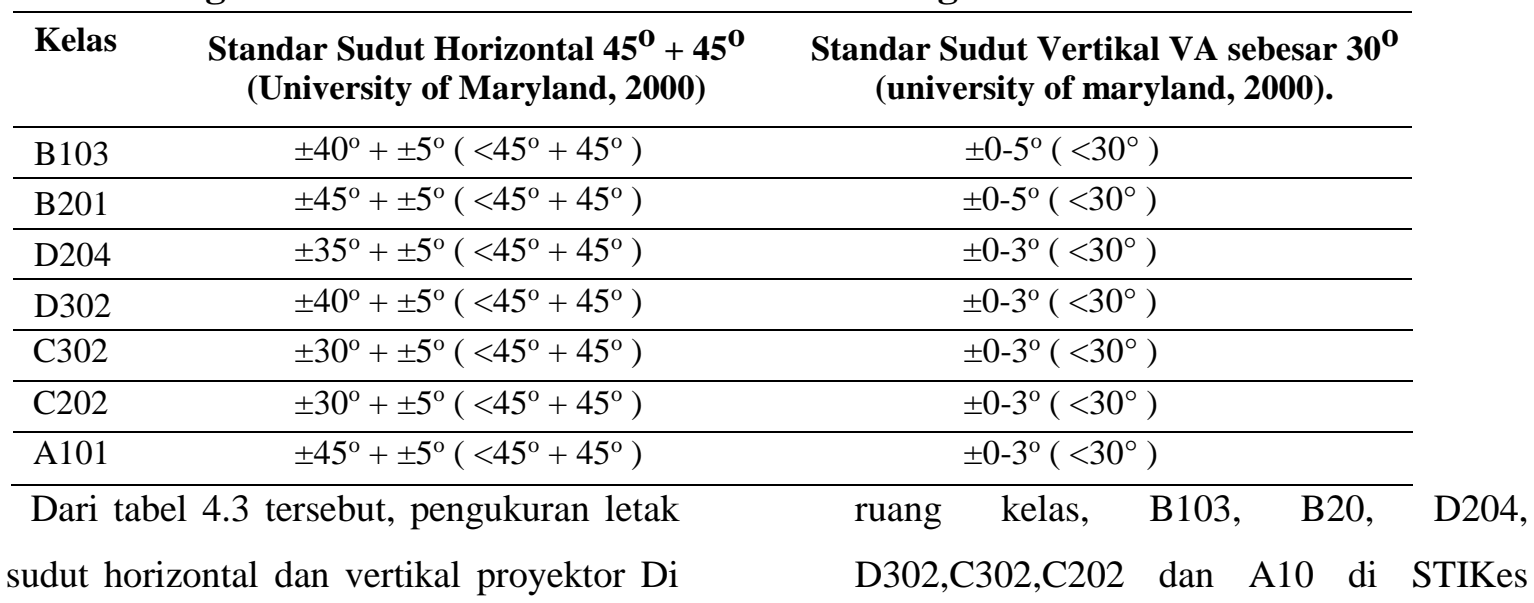


JURNAL SEHAT MASADA VOLUME XIV

Dharma Husada Bandung Tahun 2019 masih di bawah standard Univesity of Maryland Tahun 2000.

\section{KESIMPULAN}

1. Deskripsi pencahayaan di ruang kelas STIKes Dharma Husada Bandung yang telah di lakukan pengukuran 7 kelas diantaranya, ruang kelas B103 menggunakan penerangan lampu sebesar 80.15 lux dan tanpa penerangan sebesar 9.64 lux, ruang kelas B201 menggunakan penerangan lampu sebesar 226.7475 lux dan tanpa penerangan sebesar 30.965 lux, ruang kelas D204 menggunakan penerangan lampu sebesar 155.525 lux dan tanpa penerangan sebesar 68.79 lux, , ruang kelas D302 menggunakan penerangan lampu sebesar 168.665 lux dan tanpa penerangan sebesar 82.705 lux, ruang kelas C302 menggunakan penerangan lampu sebesar 52.705 lux dan tanpa penerangan sebesar 22.415 lux, , ruang kelas C202 menggunakan penerangan lampu sebesar 107.499 lux dan tanpa penerangan sebesar 30.82 lux, dan ruang kelas A101 hanya bisa menggunkan penerangan lampu saja sebesar 133.852 lux,

2. Deskripsi mengenai kejadian kelelahan mata di ketahui bahwa kejadian kelelahan mata pada mahasisa/i STIKes Dharma Husada Bandung Tahun 2019 dari 100
NOMOR 2 Juli 2020 ISSN : 1979-2344

responden paling banyak mengalami keluhan bahu

3. terasa nyeri sebanyak 84 responden ( $84 \%$ ) dan paling sedikit 24 ( $24 \%$ ) responden yang mengami keluhan pusing disetai mual.

4. Deskripsi pengukuran sudut horizontal dan vertikal di ruang kelas STIKes Dharma Husada Bandung, dari ke 7 kelas yang di ukur sudut horizontal semuanya masih di bawah standar yaitu . ruang kelas B103 $\left( \pm 40^{\circ}\right.$

5. $\left.+ \pm 5^{\circ}\right)$, ruang kelas B201 $\left( \pm 45^{\circ}+ \pm 5^{\circ}\right)$, ruang kelas D204( $\left.\pm 30^{\circ}+ \pm 5\right)$, ruang kelas D302 $\left( \pm 40^{\circ}+ \pm 5^{\circ}\right)$, ruang kelas C302 $\left( \pm 30^{\circ}\right.$ $\left.+ \pm 5^{\circ}\right)$, ruang kelas $\mathrm{C} 202\left( \pm 30^{\circ}+ \pm 5^{\circ}\right)$, dan ruang kelas A101 $\left( \pm 45^{\circ}+ \pm 5^{\circ}\right)$, sedangkan sudut vertikal semuanya dari ketujuh kelas masih sesuai standar yang berlaku yaitu $\left( \pm 0-3^{\circ}\left(<30^{\circ}\right)\right.$. Univesity of Maryland Tahun 2000.

\section{REFERENSI}

Ade, J. (2015). Tingkat Pechayaan Yang Kurang Ergonomis Pada Ruangan Kerja.

Agus \& I Made, M. (2017). Aspek Ergonomi Terkait Proses Perkuliahan Mahasiswa Semester Vii Program Studi Pendidikan Dokter Fakultas Kedokteran Universitas Udayana Tahun 2014. E Jurnal Medika, E Vol 6 No5, Mei 2017.

Ralph , C. (2012). Kinerja Dan Ruang Lingkup Penglihatan. Vision For Everyone.

Rodiah, R. L., Eka, R., \& Lokot, D. (2016). Identifikasi Kelainan Mata Dan Koreksi Tajam Penglihatan. Abdimas Talenta.

Sukanta, S. M. (2016). Perancangan Tata Letak Proyektor Yang Ergonomis 
Pada Ruang Kuliah Universitas Singaperbangsa Karawang. Lppm. Syamsul, A., \& Ira, R. (2015). Evaluasi Dan Usulan Ergonomis Posisi Perangkat Proyektor Lcd Di Kampus Akademi Teknologi Industri Padang. Seminar Nasional Tekinik Industri Bksti.

Setiawan, D. (2015). Analisis Kelelahan Mata Pekerja Sebelum Dan Sesudah

Bekerja Pada Intensitas Penerangan Dibawah Standar Di Ruangan Office Pt. Buma Jobsite Adaro.

Syamsul, A., \& Ira, R. (2015). Evaluasi Dan Usulan Ergonomis Posisi Perangkat Proyektor Lcd Di Kampus Akademi Teknologi Industri Padang. Seminar Nasional Tekinik Industri Bksti.

Taylor, \& Francis. (2005). Visual Ergonomics Hand Book. Boca Ration , London ,New York ,Singapore: T \& F Informa.

A Aziz , A. (2014). Metode Penelitian Kebidanan \& Teknik Analisis Data.

Selemba Medika.

Arikunto. (2013). Prosedur Penelitian Suatu Pendekatan Praktik. Jakarta Rineka Cipta.

Kurniasari, W. (2018). Gambaran Intesitas Pencahayaan Dan Kelelahan Mata Pada Siswa Sdn Pagadean Subang Tahun2018.

Notoatmodjo. (2012). Metode Penelitian Kesehatan. Jakarta Rineka Cipta. Sugiyono. (2013). Statistik Untuk
Penelitian. Alfabeta Cv. Bandung .

Adnyani, S. (2015). Layout Proyektor Lcd Yang Ergonomis Pada Ruang Kuliah Jurusan Teknik Elektro Universitas Mataram . Issn .

Affandi (2005). Sindrom Penglihatan Komputer (Computer vision syndrome). Majalah Kedokteran Indonesia, Volume 55, Nomer 3.

Anshel, J. (2005). Visual Ergonomics Handbook. Taylor \& Francis Grup Is The Academic Divison Of T\&F Informa Plc.

Firmansyah. (2010). Pengaruh Intensitas Penerangan Terhadap Kelelahan Mata Pada Tenaga Kerja .

Nurmayanti, D. (2009). Faktor - Faktor Yang Berhubungan Dengan Keluhan Kelelahan Mata Pada Pekerja Pengguna Komputer.

Nurmianto. (2008). Ergonomi Konsep Dasar Dan Aplikasinya. Edisi Kedua

Suraba Ya: Guna Widya Surabaya.

R Balph , C. (2011). Kinerja Dan Ruang Lingkup Penglihatan . Vision For Everyone, 54.

Listiana, Listiana , C., Rifati, D., \& Bambang, S. (2016). Analisis Intensitas Pencahayaan Di Ruang Kuliahgedung Fisika Universitas Jemberdengan Menggunakancalculux Indoor 5.0b. Jurnal Pemebelajaran Fisika, Vol 5 No.1. 